\title{
CONTRIBUIÇÃO DA VIVÊNCIA ACADÊMICA EM UM CENTRO DE CONVIVÊNCIA DE SAÚDE MENTAL NA FORMAÇÃO DO ENFERMEIRO*
}

\author{
Cínthia Verdolin Lopes ${ }^{1}$, Amanda Márcia dos Santos Reinaldo ${ }^{2}$
}

\begin{abstract}
RESUMO: Esse estudo teve como objetivo relatar a contribuição da vivência acadêmica em um Centro de Convivência de Saúde Mental para a formação do enfermeiro. Como resultado, a inserção de discentes de Enfermagem em dispositivos da rede de atenção substitutiva de saúde mental permitiu o desenvolvimento de habilidades e competências inerentes ao exercício da profissão. Ademais, essa vivência acadêmica permitiu que a formação do enfermeiro seja concordante com o conjunto de transformações, advindas da Reforma Psiquiátrica, na política, práticas, saberes e valores culturais e sociais, em relação ao sofrimento psíquico, dentro das instituições e das relações interpessoais. A interlocução entre a enfermagem e os serviços substitutivos de saúde mental contribui para o sucesso na terapêutica oferecida aos indivíduos em sofrimento psíquico, quando se supera o modelo de assistência baseado meramente na aplicação de procedimentos técnicos e de medicações.

PALAVRAS-CHAVE: Educação em enfermagem; Saúde mental; Serviços de saúde.

\section{CONTRIBUTION OF ACADEMIC EXPERIENCE IN A COMMUNITY MENTAL HEALTH CENTER IN NURSE TRAINING}

\begin{abstract}
This study aimed to report the contribution of academic experience in a Community Mental Health Center to the training of the nurse. As a result, the placing of student nurses in units of the substitutive mental health network allowed the development of skills and competencies inherent to exercising the profession. Moreover, this academic experience allowed nurse training to be in agreement with the set of transformations arising from the Psychiatric Reform in policies, practices, cultural and social knowledge, and in relation to psychological suffering, within institutions and interpersonal relationships. The dialog between Nursing and the substitutive mental health services contributed to the success in the therapy offered to individuals with mental suffering, when the care model based only on the administration of technical procedures and of medication could be overcome.
\end{abstract}

KEYWORDS: Education in nursing; Mental health; Health services.

\section{CONTRIBUCIÓN DE LA VIVENCIA ACADÉMICA EN UN CENTRO DE CONVIVENCIA DE SALUD MENTAL EN LA FORMACIÓN DEL ENFERMERO}

RESUMEN: Este estudio tuvo el objetivo de relatar la contribución de la vivencia académica en un Centro de Convivencia de Salud Mental para la formación del enfermero. Como resultado, la inserción de discentes de enfermería en dispositivos de la red de atención sustitutiva de salud mental posibilitó el desarrollo de habilidades y competencias involucradas al ejercicio de la profesión. Además de eso, esa vivencia académica permitió que la formación del enfermero se asocíe al conjunto de transformaciones que vienen de la Reforma Psiquiátrica, en la política, prácticas, saberes y valores culturales y sociales, acerca del sufrimiento psíquico, en las instituciones y en las relaciones interpersonales. La interlocución entre la enfermería y los servicios sustitutivos de salud mental contribuye para el éxito en la terapéutica ofrecida a los individuos en sufrimiento psíquico, cuando se supera el modelo de asistencia basado en la mera aplicación de procedimientos técnicos y de medicinas. PALABRAS CLAVE: Educación en enfermería; Salud mental; Servicios de salud.

*Relato das atividades do Projeto de Extensão "Oficinas terapêuticas para hábitos de vida saudável no Centro de Convivência Arthur Bispo do Rosário" do Curso de Graduação em Enfermagem da Universidade Federal de Minas Gerais - UFMG.

${ }^{1}$ Acadêmica do Curso de Graduação em Enfermagem da UFMG.

${ }^{2}$ Enfermeira. Doutora em Enfermagem Psiquiátrica. Professora do Departamento de Enfermagem Aplicada da UFMG. 


\section{INTRODUÇÃO}

Os Centros de Convivência em Saúde Mental têm como principal finalidade promover a reabilitação biopsicossocial das pessoas em sofrimento psíquico. Dessa maneira, buscam proporcionar um espaço de construção de laços sociais e de inclusão da pessoa com transtornos mentais por meio de atividades coletivas conhecidas como oficinas ${ }^{(1)}$. Essas oficinas podem contemplar temas como a arte e a música, entre outros, na forma de educação para a saúde ou de cunho profissionalizante. Quanto à educação para a saúde, existe importante relação entre o enfermeiro e esse tipo de instituição, já que uma das principais funções daquele profissional é promover a educação em saúde na comunidade na qual está inserido.

Esses dispositivos seguem a lógica antimanicomial e surgiram com o Movimento da Reforma Psiquiátrica Brasileira, cujo advento compreendeu um processo político e social complexo, com um conjunto de transformações de práticas, saberes, valores culturais e sociais acerca da loucura. Como resultado, esse Movimento político-social busca promover a desinstitucionalização nos hospitais psiquiátricos, reduzindo o número de leitos e criando as redes extra-hospitalares de atenção psicossocial. Além de representar um importante marco para a mudança do paradigma negativo de periculosidade associado aos cidadãos portadores de sofrimento psíquico. O processo da Reforma, no Brasil, então iniciado por volta da década de 1970, culminou com a Lei 10.216, de 6 de abril de 2001, conferindo proteção aos indivíduos em sofrimento psíquico e redimencionando o modelo assistencial de saúde mental. Os Centros de Convivência advêm a partir dessa busca por um efetivo lugar social para portadores de transtorno mental, por meio de ações que ampliem a autonomia e preocupados com a melhoria da qualidade de vida deles.

A vivência acadêmica em um Centro de Convivência de Belo Horizonte - Minas Gerais, permitiu visualizar a importância da autonomia dos indivíduos em sofrimento psíquico e também da interlocução entre as práticas de Enfermagem de educação para a saúde com a Saúde Mental. Na Escola de Enfermagem da Universidade Federal de Minas Gerais existe um projeto de extensão, por meio do qual os alunos do Curso de Graduação em Enfermagem realizam oficinas lúdicas e interativas de educação para a saúde, tratando de temas variados com os usuários. Por meio das atividades, os discentes do projeto de extensão desenvolvem habilidades inerentes ao exercício da Enfermagem tais como: a comunicação, a gerência de grupos, a liderança e a reflexão crítica acerca dos diversos desafios que as ações de educação para a saúde exigem.

Em vista dos aspectos mencionados, este estudo objetivou relatar a contribuição da vivência acadêmica em um serviço substitutivo de saúde mental para a formação profissional enfermeiro.

\section{MÉTODO}

Trata-se de um relato de experiência acerca da realização de oficinas terapêuticas em um Centro de Convivência de Belo Horizonte, no primeiro semestre de 2010, por acadêmicas de enfermagem da Universidade Federal de Minas Gerais. Foram realizados 11 encontros com os indivíduos em sofrimento psíquico, havendo, em média, 10 participantes por encontro. A adesão dos usuários às atividades realizadas é espontânea, sendo convidados por meio de cartazes dispostos no Centro de Convivência e também verbalmente.

Foram trabalhadas temáticas variadas referentes ao cuidado de si (Higiene corporal e Saúde Bucal), à educação para a saúde (Hipertensão, Diabetes, Doenças Sexualmente Transmissíveis) e referentes a questões sociais (Preconceito, Deficiência, Exercício da Cidadania). Diversas estratégias foram adotadas, como jogos, gincanas, dinâmicas e filmes para o exercício dialógico, lúdico e interativo dos temas, eleitos conforme sugestão dos participantes em concordância com os assuntos previstos no cronograma anual das discentes.

\section{DIÁLOGO ENTRE ENFERMAGEM E CENTRO DE CONVIVÊNCIA DE SAÚDE MENTAL}

O objetivo do projeto de extensão "Oficinas terapêuticas para hábitos de vida saudável no Centro de Convivência Arthur Bispo do Rosário" é promover oficinas de educação para saúde e cuidados de si, por estudantes da graduação em Enfermagem da Universidade Federal de Minas Gerais. Esse projeto existe desde 2008, bem como as oficinas, sendo coordenado por uma docente da Escola de Enfemagem, doutora em Enfermagem Psiquiátrica. Os alunos se inserem no projeto por meio do processo de seleção de bolsas da universidade, podendo também ser voluntários. A docente orienta os estudantes e esses são responsáveis pela elaboração semanal das oficinas de Enfermagem. Nas oficinas, as discentes buscam sensibilizar os usuários para a importância do autocuidado e da promoção da própria qualidade de vida e de saúde. 
Com o objetivo de promover a aproximação dos alunos da graduação em Enfermagem nas atividades das oficinas. Esta técnica permite ampliar as possibilidades de atuação para os enfermeiros sobre seu papel para a atuação dos futuros profissionais na realidade de reestruturação da assistência psiquiátrica a partir do trabalho em diferentes cenários. Esses ainda têm insuficiente visibilidade na comunidade e na rede assistencial como locais terapêuticos, sendo necessário os alunos descobrirem que espaços são esses e desenvolverem suas potencialidades o mais breve possível ${ }^{(2)}$.

A interlocução entre a enfermagem e os serviços substitutivos de saúde mental torna possível o sucesso na terapêutica oferecida às pessoas em sofrimento psíquico, quando se supera o modelo de assistência baseado meramente na aplicação de procedimentos técnicos e de medicações. O enfermeiro, pautado em princípios éticos, deve ser capaz de conhecer e intervir nas situações de saúde e doença, buscando não só identificar as dimensões biopsicossociais da pessoa assistida, mas também promover a saúde do ser humano de forma integral ${ }^{(3)}$.

Dessa forma, entre as várias possibilidades de intervenção pelo profissional enfermeiro ${ }^{(4)}$, tem-se a área da saúde mental, cuja demanda está na capacitação dos profissionais de saúde para a compreensão e reelaboração dos determinantes psicossociais da loucura. Também para transformarem saberes e práticas, até então constituídos, em relação ao sofrimento psíquico; de articularem conhecimentos adquiridos com novos modos de sociabilidade e de produção de valor social, envolvidos em saúde e em saúde mental. É possível aos enfermeiros perceberem a complexidade de suas práticas e de, efetivamente, desenvolverem novas ações como formas de pensar e agir, reinventando modos de se lidar com a realidade do sofrimento psíquico ${ }^{(4)}$.

\section{RESULTADOS}

Para os participantes das oficinas promovidas pelas discentes de enfermagem, as atividades funcionaram como instrumento de aquisição e construção de saberes em saúde. Também para sensibilizá-los para a dispersão dos saberes adquiridos, com familiares, amigos e comunidade. Além disso, os usuários destacaram a mudança positiva nos hábitos de vida, de modo a prevenir agravos e promover melhoria na qualidade de vida.

Para os docentes, as oficinas configuraram-se como um espaço de exercício de habilidades inerentes ao processo de educar, tais como troca e aprimoramento de conhecimentos e estímulo à autonomia dos indivíduos. Além disso, percebe-se alteração positiva da concepção biologista, típica do início da formação acadêmica, para uma lógica que busca ampliar o conceito de saúde, abrangendo prevenção, promoção e reabilitação de forma integral e holística. Quanto às habilidades e competências do enfermeiro, ressalta-se que a elaboração e aplicação das atividades lúdicas e interativas resultam em exercício prático da comunicação, da gerência de grupos, da liderança e da reflexão crítica acerca dos diversos desafios que as ações de educação para a saúde exigem.

\section{DISCUSSÃO}

As atividades das oficinas do referido relato podem ser vistas através do enriquecimento dos indivíduos, de valorização da expressividade, de descoberta e de potencialização das capacidades próprias. Elas apresentam a possibilidade dos usuários estabelecerem vínculos de convivência uns com os outros e laço de cuidado. Também como meio de obter conhecimento e informação acerca dos diversos assuntos de saúde, os quais são abordados nas oficinas. Nesse espaço de criação, os usuários foram escutados como sujeito, puderam dar vazão às próprias subjetividades e estabelecer seus próprios limites e regras, não havendo, portanto, padrão a ser seguido nas atividades propostas.

Quanto ao desenvolvimento das discentes como futuros enfermeiros, a vivência apresentada teve importante papel para que a formação acadêmica seja congruente com a lógica antimanicomial da Reforma Psiquiátrica. O Centro de Convivência exige um afastamento da concepção biomédica, de mera aplicação de medicações e hospitalização permanente, e aproximação da ideia de outras terapêuticas, como as oficinas, para efetiva reabilitação biopsicossocial da pessoa em sofrimento psíquico e para sua reinserção na sociedade.

\section{CONSIDERAÇÕES FINAIS}

Conforme relatos dos participantes durante as oficinas de Enfermagem tal estratégia lhes possibilita o desenvolvimento de senso crítico acerca dos diversos assuntos de saúde abordados nas oficinas.

Para a formação, esta vivência contribui de forma significativa para o exercício de competências exigidas ao enfermeiro, já que na abordagem das oficinas é preciso ter iniciativa, tomada de decisões, criatividade, capacidade resolutiva, abordagem integral do cuidado, exercício da escuta terapêutica, liderança e trabalho em 
equipe. Ainda, a partir desse tipo de experiência acadêmica torna-se possível a desmitificação dos paradigmas de periculosidade e a redução de preconceitos acerca da loucura. Também contribuir na reinterpretação da terapêutica em saúde mental, do modelo asilar para a lógica antimanicomial. As oficinas, como recurso terapêutico, permitem um espaço de ressocialização e descontroem o esteriótipo da pessoa em sofrimento como alguém incapaz ou de pouca disposição para o conhecer, o fazer e o sonhar.

A experiência acadêmica relatada apontou a inserção de discentes de enfermagem na rede substitutiva de saúde mental como um meio facilitador do desenvolvimento de habilidades e competências inerentes ao exercício da enfermagem e concordantes com os eixos político-sociais vigentes. Além disso, as oficinas terapêuticas de enfermagem em saúde mental podem ser apontadas como instrumentos fundamentais para a disseminação da lógica preventiva e comunitária dos cuidados à saúde, e para a promoção de um espaço de ressocialização e de promoção pessoal para os indivíduos em sofrimento psíquico.

\section{REFERÊNCIAS}

1. Ministério da Saúde(BR). Portaria SAS/MS no 396 de 07 de julho de 2005. Dispõe sobre as diretrizes gerais para o Programa de Centros de Convivência e Cultura na rede de atenção em saúde mental do Sistema Único de Saúde. Diário Oficial da República Federativa do Brasil. Brasília, [Internet] 07 jul 2005 [acesso em 10 abr 2011]. Disponível: http://tr2001.saude.gov.br/sas/ PORTARIAS/Port2005/PT-396.htm

2. Damasceno EC, Reinaldo AMS. Oficinas terapêuticas para hábitos de vida saudável no Centro de Convivência Arthur Bispo do Rosário: relato de experiência. Cogitare enferm. [Internet] 2009;14(1) [acesso em 06 jul 2011]. Disponível: http://ojs.c3sl.ufpr. br/ojs2/index.php/ cogitare/article/view/14144/9521

3. Fernandes JD, Sadigursky D, Silva RMO, Amorim AB, Teixeira GAS, Araújo MCF. Ensino da enfermagem psiquiátrica/saúde mental: sua interface com a Reforma Psiquiátrica e diretrizes curriculares nacionais. Rev Esc Enferm USP. [Internet] 2009;43(4) [acesso em 06 jul 2011]. Disponível: http://www.scielo.br/pdf/reeusp/ v43n4/a31v43n4.pdf

4. Soares AN, Silveira BV, Reinaldo AMS. Serviços de saúde mental e sua relação com a formação do enfermeiro. Rev Rene. [Internet] 2010;11(3) [acesso em 06 jul 2011]. Disponível: http://www.revistarene.ufc.br/ vol11n3_pdf/a05v11n3.pdf

Cogitare Enferm. 2012 Out/Dez; 17(4):775-8 